\title{
CAMCOG detected dementia and cognitive impairment in Parkinson's disease
}

\author{
Hobson P, Meara J. The detection of dementia and cognitive impairment in a community population of elderly people with \\ Parkinson's disease by use of the CAMCOG neuropsychological test. Age Ageing 1999 Jan;28:39-43.
}

\section{Question}

In community dwelling of elderly people with Parkinson's disease (PD), how do the cognitive section of the Cambridge Examination for Mental Disorders (CAMCOG) and the Mini-Mental State Examination (MMSE) perform (compared with $D S M-I V$ ) in detecting dementia and cognitive impairment?

\section{Design}

Blinded comparison of measures on the CAMCOG and the MMSE with $D S M-I V$ criteria for dementia.

\section{Setting}

Communities in North Wales, UK.

\section{Patients}

126 patients who were $>60$ years of age (mean age 74 y), lived at home, and met clinical diagnostic criteria for probable PD. Patients with drug induced PD or other forms of parkinsonism were excluded.

\section{Description of tests and diagnostic standard}

All patients were screened with the CAMCOG and the MMSE. The DSM-IV criteria were applied by an assessor who was blind to the results of the CAMCOG and the MMSE.

\section{Main outcome measures}

Sensitivity and specificity of the tests using a CAMCOG score of $\leqslant 80$ and an MMSE score of $\leqslant 24$ for dementia.

\section{Main results}

56 patients (44\%) met the DSM-IV criteria for dementia. Both the CAMCOG and the MMSE had high sensitivity for detecting dementia; the CAMCOG had high specificity but the specificity of the MMSE was low (table). The CAMCOG showed differences between patients with and without dementia on all 8 subscales (orientation, language, memory, attention, praxis, calculation, abstract thinking, and perception). Greater age was associated with poor performance on subscales of language, memory, attention, calculation, and perception; men did better than women on the subscales of attention and calculation; and patients in professional or managerial and skilled non-manual classes did better than unskilled manual classes on the subscales of praxis and abstract thinking.

\section{Conclusions}

In a community dwelling of elderly people with Parkinson's disease, the cognitive section of the CAMCOG and the MMSE had high sensitivity for detecting dementia and cognitive impairment. The CAMCOG was more specific than the MMSE.

The cognitive section of the Cambridge Examination for Mental Disorders (CAMCOG) and the Mini-Mental State Examination (MMSE) for detecting dementia in Parkinson's disease

\begin{tabular}{lllllll}
\hline $\begin{array}{l}\text { Test (cut } \\
\text { point) }\end{array}$ & $\begin{array}{l}\text { Sensitivity } \\
(95 \% \text { CI })\end{array}$ & Specificity $(C I)$ & $+P V^{*}$ & $-P V^{*}$ & $+L R^{*}$ & $-L R^{*}$ \\
\hline $\begin{array}{c}\text { CAMCOG } \\
(\leqslant 80)\end{array}$ & $\begin{array}{l}95 \% \\
(85 \text { to } 99)\end{array}$ & $94 \%(86$ to 98$)$ & $93 \%$ & $96 \%$ & 16.6 & 0.06 \\
$\begin{array}{c}\text { MMSE } \\
(\leqslant 24)\end{array}$ & $\begin{array}{l}98 \% \\
(90 \text { to } 100)\end{array}$ & $77 \%(66$ to 86$)$ & $77 \%$ & $98 \%$ & 4.3 & 0.02 \\
\hline
\end{tabular}

* PV, LR, and CI calculated from data in article and defined in the glossary.

Source of funding: no external funding.

For correspondence: Dr Peter Hobson, University Department of Geriatric Medicine (North Wales), For correspondence: Dr Peter Hobson, University Department of Geriatric Medicine (North Wales), 534668.Emailpeterhobsom@hotmail.com and jolymeara@hotmail.com.

\section{Commentary}

The introduction of new specific treatments for dementia has increased the need to improve instruments that screen for cognitive impairment. Preliminary evidence exists to show that Lewy body dementia, often associated with PD, may respond better to some acetylcholinesterase inhibitors than Alzheimer's disease.

The well designed study by Hobson and Meara includes a representative community sample of patients with PD, and uses validated screening instruments. The CAMCOG was superior to the MMSE but this is not surprising considering the CAMCOG includes all the questions of the MMSE, is more comprehensive (CAMCOG has a maximum score of 106 compared with the maximum of 30 in the MMSE), and includes cognitive functions not covered by the MMSE, 2 of which may have particular associations with PD. The first association is ideomotor praxis/ apraxia (impaired timing sequencing and spatial organisation of gestural movements) which were present in 27\% of patients with PD in 1 recent study, and not necessarily associated with dementia. ${ }^{2}$ The second association is with abstract thinking. Frontal lobe deficits are common in Lewy body dementia because of disruption to the subcortical-frontal pathways.

The 25 minutes to administer CAMCOG is probably too time consuming as a first line screening tool, especially for general practitioners, geriatricians, and neurologists who see many more patients with PD than do old age psychiatrists. Informant questionnaires may be more practical for first line screening, particularly in combination with the MMSE, ${ }^{3}$ and are suitable for the physically ill. ${ }^{4}$

For psychiatrists, the important message from this study is that patients with PD frequently have cognitive deficits which may be inadequately assessed by the MMSE alone. The CAMCOG may be a useful additional tool to assess these patients.

Seena Fazel, MBChB, MRCPsych Daniel Harwood, BM BS, MRCPsych University of Oxford Oxford, UK

Lebert F, Pasquier F, Souliez L, et al. Int J Geriatr Psychiatry 1998:13:516-9.

atr Psychiatry 1998;13.516-9. Leiguarda RC, Pramstal

Brain 1997;120:75-90. Mackinnon A, Mulligan R. Am J Psychiatry 1998;155:1529-35.

4 Harwood DM, Hope T, Jacoby R. Age Ageing 1997;26:31-5. 